Vol. 2, October 2019

\title{
A High School Level Health and Disease-Focused Biology Curriculum Promotes Higher Level Skills in Nutrition Literacy
}

\author{
Stephanie A. Tammen ${ }^{1}$, Karina Meiri', Russel Faux², and Berri Jacque ${ }^{1}$
}

${ }^{1}$ Center for Translational Science Education, Tufts University School of Medicine, Boston, MA; ${ }^{2}$ Davis Square Associates, Somerville, MA

Keywords: Nutrition literacy, health literacy, high school, biology, health science

Publication Date: October 16, 2019

DOI: https://doi.org/10.15695/jstem/v2i1.17

\begin{abstract}
Objective: To determine the efficacy of a high school biology curriculum focused on promoting nutrition literacy skills. Design: High school students participated in a six-week biology curriculum focused on the three subdomains of nutrition literacy: functional use of factual knowledge (FNL); interactive skills in seeking out information (INL); critical interpretation and analysis (CNL). We used a mixed-methods, change-over-time model that leverages longitudinal aspects of instructor practice and students' development. Pre- and posttest measures of FNL, INL and CNL were administered. Students were also given a retrospective pre-post online survey to measure interactive nutrition literacy and self-efficacy towards learning about nutrition topics. Participants: A total of 111 high school 11th and 12th grade students from four sections of a Biology II course participated. Results: Students' overall NL scores improved $(P<0.0001)$ and they also showed gains in each subdomain (FNL, INL and CNL, $P<0.0001$ ). Self-efficacy toward learning about nutrition also increased $(P<0.0001)$. Students reported increased communication about the topics with family and peers who were neither classmates or friends $(P<0.0001)$. Conclusions: Participation improved nutrition literacy in each of the subdomains, as well as self-efficacy. Self-efficacy was strongly related to increased communication.
\end{abstract}

\section{INTRODUCTION}

Nearly $45 \%$ of all United States adults, particularly in underserved communities, have inadequate health literacy (HL), defined by the Institute of Medicine as the 'degree to which individuals have the capacity to obtain, process, and understand basic health information and services needed to make appropriate health decisions' (Kindig et al., 2004). The deficit results in a lack of understanding of disease management and health-promoting behaviors, significantly contributing to poor health outcomes (Kindig et al., 2004; Berkman et al., 2011; Koh et al., 2012). Nutrition literacy (NL) has been defined in parallel with general HL as 'the ability to find and elaborate on nutrition information and make conclusions regarding health issues' (Silk et al., 2008), and inadequate NL also likely impacts nutrition-related diseases, such as obesity ( $30 \%$ of US boys and girls are obese, compared with worldwide rates of $15 \%$ ) and diabetes, which has increased 4-fold since 1980 . As a result, $33 \%$ of US adults are currently pre-diabetic while $8.9 \%$ have type 2 diabetes (Centers for Disease Control and Prevention, 2017).

The Institute of Medicine has recommended using health education to promote health literacy (Kindig et al., 2004; Berkman et al., 2011; Koh et al., 2012). However, the parameters of when this education should begin and what it should look like have been unclear (Nutbeam, 2000). The World Health Organization in its most recent declaration (2016) has attempted to define when, stating that "health literacy is founded on ... life-long learning. To achieve this, it must be an integral part of the skills and competencies developed over a lifetime, first and foremost focused in the school curriculum". This strategy makes sense since school is usually the last occasion in which an entire cohort of the population gathers to learn in a single venue (Cohen and Syme, 2013).

The challenge now becomes creating school curricula that promote NL, which raises the question of where such curricula should be situated. While health education classes may seem like an obvious venue, their focus in the United States is commonly on promoting specific behaviors (such as healthy eating), rather than developing the higher-level NL skills required to understand and evaluate health-related claims and to assess risk. In contrast, fostering these higher-level skills in the context of general science literacy is already an important element of the high school science curriculum, with science literacy pertaining to life sciences taught as part of the biology curriculum (National Research Council, 2012). It therefore follows that the biology classroom is an important and underexploited venue for NL-focused curricula.

Curricula focused on the three subdomains of NL need to be designed to foster skills like critical understanding, claims evaluation and risk assessment (Jacque et al., 2016). 
With respect to the content vehicle, contextualizing life science principles to health and disease helps students transfer general science literacy skills to a pertinent setting, such as evaluating the merits of a dietary claim (Detterman and Sternberg, 1993; Merriam and Leahy, 2005; Haskell, 2000). We have demonstrated that high school students particularly value topics in health and disease and become deeply engaged with learning when they see the science behind their real-world experiences modeled in the biology classroom (Jacque et al., 2013). Hence teaching NL in the context of health and disease in a biology classroom seemed like a promising approach to building high level nutritional knowledge, skills and NL.

In response to the challenge of developing effective HL curricula for schools The Center for Translational Science Education at Tufts University School of Medicine (CTSE) has created 'The Great Diseases' a comprehensive high school science curriculum focused on health and disease (Jacque et al., 2013). Targeted to Biology II, commonly an elective course without a state-mandated syllabus, the Great Diseases curriculum focuses on four diseases of global significance: metabolic disease, infectious disease, cancer and neurological disorders. Each disease topic occupies a standalone module that lasts about 6 weeks. The development and implementation of the Great Diseases curriculum has been described elsewhere (Jacque et al., 2013; Malanson et al., 2014; Tammen et al., 2018).

Here we evaluated the metabolic disease (MD) module that focuses on NL through the prism of nutrition-related diseases. Velardo has identified three parallel subdomains under the NL umbrella: Functional Nutrition Literacy (FNL) refers to the skills required to apply basic factual knowledge, such as understanding the components of a healthy diet. Interactive Nutrition Literacy (INL) refers to the development of the more complex skills required to identify, navigate and communicate nutrition information and Critical Nutrition Literacy (CNL) involves proficiency in evaluating and interpreting scientific data related to nutrition (Nutbeam, 2000; Velardo, 2015).

This case study is a secondary analysis of data from a repeated measures design study following enactment of the MD module. Its objective is to evaluate how effective the MD module is in promoting the three subdomains of NL. Three hypotheses are addressed: First that specific elements of the curriculum would be effective at promoting knowledge and skills development related to FNL and CNL. Second that the curriculum would foster the self-efficacy towards learning necessary for further information-seeking behaviors outside the classroom (Berkman et al., 2011; Austin et al., 2012; Basu and Dutta, 2008; Brittner and Pajares, 2006; Zeldin et al., 2008) and finally that participation would provide evidence of behavior change indicative of increased self-efficacy.

\section{METHODS}

Intervention Overview. The MD module occupies sixweeks in the year-long high school Great Diseases curriculum and aligns with the following crosscutting science education standards that are particularly relevant to both general science literacy and NL: (a) asking questions and defining problems (b) evaluating and communicating information, and (c) analyzing and interpreting data (Cohen and Syme, 2013). The MD module is subdivided into five units, each of which comprises three to seven lessons (28 lessons in total). Each unit poses a key question that nutrition experts deemed essential to building fundamental NL and intensively scaffolds both INL and CNL onto an FNL base (Table 1). For example, MD unit 1 'What's in your food?' provides an integrated understanding of the different components in food, including macro and micronutrients, food additives and contaminants (FNL). Students then engage in active inquiry into the nature of the calorie and the limitations of how calories are measured (CNL). To address INL they role play different stakeholders in the food production chain. In unit 2 'How does your body use food?' the molecular processes behind glucose, lipid and protein metabolism serve as a basis for understanding how the body maintains blood glucose and energy homeostasis under different physiological conditions (FNL). Then Unit 3 'What is metabolic disease?' further scaffolds INL and CNL onto this FNL base by investigating how interactions between the neural regulation underlying hunger and satiety and the reward pathway in the brain collaborate to drive nutrition behavior. In both cases type 2 diabetes mellitus is used as a case study to exemplify how disorders in glucose homeostasis can lead to disease. In unit 4 'How do you identify 'good' and 'bad' food?' students begin to focus on the INL and CNL skills behind identifying, evaluating and communicating nutritional information related to the science underlying metabolic disease: They address limitations of study design, in particular, which methods are feasible in humans, as well as how to interpret data, especially highly variable human data. Finally, in unit 5 'How does all this knowledge apply to me?' students identify a nutrition claim and critically evaluate online resources using all key components of INL and CNL. We found that designing a curriculum that integrates these complex concepts effectively required active collaboration between nutrition science experts and pedagogical experts (high school biology teachers) facilitated by CTSE members; neither group had the skills to produce this kind of material on their own (Tammen et al., 2018).

Successful implementation of novel curricula requires adequate teacher support (Garet et al., 2001; Beyer et al., 2009). We therefore created, in parallel, comprehensive educative materials for teachers comprising a content primer and lesson plans with associated activities. One important innovation is a narrative embedded within the lesson plans that 
Table 1. NL subdomains and pedagogical approaches in the Great Diseases module: Metabolic Disease. The module is divided into 5 units, each of which represents a fundamental question about nutrition and metabolic disease. Each unit has from 3-6 lessons (28 lessons in total). Each of the lessons focusses on one or more of the NL subdomains (FNL, INL and $C N L)$. The lessons have been aligned to the Next Generation Science standards. The majority employ inquiry-based pedagogy.

\begin{tabular}{|c|c|c|c|c|}
\hline \multicolumn{5}{|l|}{ Unit 1: What's in your food? } \\
\hline 1.1 What does 'food' mean? & $\mathrm{F}$ & & & * \\
\hline 1.3 How clean is your food? & $\mathrm{F}$ & & & \\
\hline $\begin{array}{l}\text { 1.4 What foods are in your food? Nutrients and the calorie } \\
\text { (part 1) }\end{array}$ & $\mathrm{F}$ & I & & * \\
\hline $\begin{array}{l}1.5 \text { What foods are in your food? Nutrients and the calorie } \\
\text { (part 2) }\end{array}$ & $\mathrm{F}$ & & & \\
\hline 1.6 How your lifestyle impacts your nutrition and caloric needs & $\mathrm{F}$ & I & $\mathrm{C}$ & * \\
\hline \multicolumn{5}{|l|}{ Unit 2: How does your body use food? } \\
\hline 2.1 Digestion - From the mouth to the bloodstream & $\mathrm{F}$ & & & * \\
\hline 2.2 Metabolism - How do your cells release energy from food? & $\mathrm{F}$ & I & & * \\
\hline 2.3 Glucose homeostasis in the blood - The metabolism game & $\mathrm{F}$ & I & & \\
\hline 2.4 Glucose homeostasis in the blood & $\mathrm{F}$ & & & \\
\hline 2.5 Disorders of metabolism - where do things go wrong? & $\mathrm{F}$ & I & & * \\
\hline 2.6 Maintaining homeostasis as the demands on the body & $\mathrm{F}$ & I & $\mathrm{C}$ & * \\
\hline
\end{tabular}
change

\begin{tabular}{|c|c|c|c|c|}
\hline Unit 3: What is metabolic disease? & & & & \\
\hline 3.1 What is obesity and how does BMI relate? & $\mathrm{F}$ & I & & * \\
\hline 3.2 What is 'fast' and 'slow' metabolism? & $\mathrm{F}$ & $\mathrm{I}$ & & \\
\hline 3.3 What makes you feel hungry or full? & $\mathrm{F}$ & & & * \\
\hline 3.4 Can you become addicted to food? & $\mathrm{F}$ & I & & * \\
\hline $\begin{array}{l}3.5 \text { Homeostasis gone awry: how the satiety pathway relates } \\
\text { to obesity }\end{array}$ & $\mathrm{F}$ & I & $\mathrm{C}$ & * \\
\hline 3.6 How does obesity lead to disease? & $\mathrm{F}$ & I & & * \\
\hline 3.7 Metabolic mystery patient lab & $\mathrm{F}$ & I & $\mathrm{C}$ & * \\
\hline \multicolumn{5}{|l|}{ Unit 4: How do you identify 'good' and 'bad' food? } \\
\hline 4.1 What is nutrition science? & $\mathrm{F}$ & I & $\mathrm{C}$ & $*$ \\
\hline 4.2 Good' vs 'bad' food - how do you tell? & $\mathrm{F}$ & I & $\mathrm{C}$ & \\
\hline 4.3 Contradictory messages about 'good' and 'bad' foods (1) & $\mathrm{F}$ & I & $\mathrm{C}$ & * \\
\hline 4.4 Contradictory messages about 'good' and 'bad' foods (2) & $\mathrm{F}$ & I & $\mathrm{C}$ & $*$ \\
\hline 4.5 How to identify correlations in data & $\mathrm{F}$ & I & $\mathrm{C}$ & * \\
\hline 4.6 Should we treat obesity with behavior therapies? & $\mathrm{F}$ & I & $\mathrm{C}$ & \\
\hline \multicolumn{5}{|l|}{ Unit 5: How does all this knowledge apply to you? } \\
\hline $\begin{array}{l}5.1 \text { How can you use what you know to evaluate nutritional } \\
\text { claims? }\end{array}$ & $\mathrm{F}$ & 1 & $\mathrm{C}$ & * \\
\hline 5.2 Searching for scientific resources & $\mathrm{F}$ & I & $\mathrm{C}$ & * \\
\hline 5.3 How can you use what you know to evaluate nutritional & $\mathrm{F}$ & I & $\mathrm{C}$ & * \\
\hline
\end{tabular}
claims?

F, Functional nutrition literacy; I, Interactive nutrition literacy; $C$, Critical nutrition literacy; *, Inquiry-based pedagogy.

contextualizes the critical learning components and models how classroom discussions might evolve so the teacher can situate the content in a life-relevant health-related context specifically focused on the three elements of NL. In addition, we provide supporting videos that model the pedagogical practices and facilitate implementation and assessments. Students themselves receive workbooks containing extra readings and quizzes. Enacting teachers can also participate in our Modeling for Fidelity program program that pairs the instructor with a subject matter and pedagogical specialist for mentoring in how to use the curricular materials. The Modeling for Fidelity approach has been shown to promote fidelity of implementation and curricular adaptation and is available to all teachers who use the curriculum (Malanson et al., 2014). In this case, structured Modeling for Fidelity mentoring included weekly in-person or virtual interactions to prepare for upcoming lessons and to provide opportunities for teachers to tailor adaptations to suit specific classroom needs and to reflect on outcomes from the previous week. All the materials are freely available on-line (http://sites. tufts.edu/greatdiseases).

Participants. This case study took place in a public exam school in New England. The curriculum was taught within an elective Biology II course. The enacting teacher, who had participated in the collaborative co-design project to create the curriculum, volunteered to participate in this study. She received Modeling for Fidelity support during implementation of the MD module. A total of 111 high school 11th and 12th grade students from four sections participated in the module and 83 (75\%) reported data on gender, ethnicity and race (Supplementary Table 1). No students refused to participate in the study, however only 98 (92\%) completed both the pre- and post-nutritional literacy inventory and only 77 (68\%) completed the retrospective pre-post surveys. This study was conducted according to the guidelines laid down in the Declaration of Helsinki and all procedures involving research study participants were approved by Tufts University School of Medicine's Internal Review Board. Students over 18 years of age provided written consent, for students under 18 written parental consent and written student assent was provided to confirm participation in the study.

Study Design. We used a mixed-methods, change-overtime model that leverages longitudinal aspects of instructor practice and students' development. To address the research questions, we analyzed data including pre-post tests, surveys and student artifacts. The comparison group took the pre-test measure to establish baseline knowledge using the measures of nutritional literacy within students from the same school who had also taken Biology I and participated in other modules of the GD curriculum that provided exposure to HL skills acquisition, but had not experienced the MD intervention focused on the three NL subdomains. Self-efficacy was probed with surveys that were given in a retrospective prepost format to minimize Type II errors.

Measures. The NL subdomains were evaluated on paper-based pre-post tests given within the normal class period. Students were told that the pretest was a way for them 
to explain their initial understanding, and that their performance would not affect their grades. Students were given the post-test as a final exam for the course. Both questions and answers were returned to CTSE for grading.

FNL and CNL problem-solving skills were measured with 10 multiple choice questions, two diagram labeling questions, and two short answer questions. Questions were designed to avoid a plateau effect and points were subtracted for incorrect answers to the multiple choice and diagram questions. A grading rubric for the short answers was established by nutrition content experts: Each short answer was graded by two evaluators and their scores averaged (inter-rater reliability was 0.90 for the pre-test, and 0.93 for the post-test). The questions were reliable: Cronbach's alpha was 0.79 above the accepted 0.70 threshold for reliability.

INL and CNL were evaluated using a case-based approach in which students evaluate a clinical case study based on their FNL about the metabolism and physiology of glucose homeostasis. The case required students to interpret graphs and address five short-answer questions about the challenges presented by the physiological scenarios. The grading rubric was established by nutrition content experts and each student's response was graded by two evaluators and averaged (the inter-rater reliability was 0.89 before the module and 0.92 after the module).

Behavior change associated with INL was evaluated from communication within students' social networks and measured as part of the retrospective pre-post survey administered at the end of the module and done on-line as homework. The survey had six questions and used a six-point Likert-type response scale, $(1=$ low, $6=$ high $)$.

Self-efficacy towards learning about NL topics was measured as part of the retrospective pre-post online survey described above. There were nine questions and answers also used a six-point Likert-type response scale, $(1=$ low, $6=$ high). The reliability value of the survey (Cronbach's alpha) was 0.9 .

Data Analysis. Normality for each variable was determined with the D'Agostino and Pearson normality test. Wilcoxon matched pairs signed rank analysis was conducted when data was not normally distributed. A post-hoc Bonferroni correction was used to adjust for multiple (6) comparisons within the pre-post-tests and multiple (7) comparisons within the communication survey. The alpha value was adjusted to 0.008 and 0.007 respectively. A two-tailed $\mathrm{P}<0.05$ was considered significant for all other analyses. Effect size was determined with Hedge's g. The relationship between FNL, INL (measured by the communication survey) and self-efficacy was determined with a Spearman correlation coefficient. Data analysis was completed using Prism 7 (version 7.0d, GraphPad Software Inc., 2017) SATA (version 1.1 2010), R and Microsoft Excel (version 16.16.1 2018).

\section{RESULTS}

Knowledge and Skills Gains Following Participation in the Curriculum. The pre-test scores of the participants were similar to the comparison group $(\mathrm{P}=0.16)$. Participating in the intervention significantly increased the average pre- to post-test score $(\mathrm{P}<0.0001$, Wilcoxon matched pairs signed rank test, Table 2). Thus, the curriculum overall was effective in conveying MD-related, NL-focused material to the students. To investigate whether the post-test demonstrated individual gains in each of the three NL subdomains, we disaggregated the test to isolate questions that addressed each subdomain individually:

Table 2: Grouped and Paired Pre-post gains in Knowledge and Skills related to FNL and CNL subdomains. Gains in knowledge and skills related to nutrition were determined from aggregate scores on pre-post tests and from individual questions designed to probe each subdomain individually - the numbers of those questions as they appeared to students are listed in the table below. Results are shown as mean \pm (S.D.) and analyzed either by (a) un-paired t-test compared with the comparison group; (b)Wilcoxon matched pairs signed rank test compared with the pre-test (***) or (c) by paired t-test compared with the pre-test ( $\mathrm{M})$. Effect size was determined by Hedge's $g$ (large effect size is >1).

\begin{tabular}{|c|c|c|c|c|c|c|c|}
\hline & $\begin{array}{l}\text { Pre-test } \\
\text { Mean }(\%)\end{array}$ & (SD) & $\begin{array}{l}\text { Post-test } \\
\text { Mean (\%) }\end{array}$ & (SD) & $\begin{array}{l}\text { Effect size } \\
\text { (Hedge's g) }\end{array}$ & $\mathrm{P}$ & $\mathrm{n}$ \\
\hline \multicolumn{8}{|l|}{ (a) Aggregate data } \\
\hline Comparison Group & 16.8 & 13.1 & & & 0.25 & (a) & 62 \\
\hline Study group & 26.9 & 10.5 & 70.9 & 14.3 & 4.1 & $(b)^{* * *}$ & 98 \\
\hline \multicolumn{8}{|c|}{ (b) Data by NL subdomain } \\
\hline Functional NL 13 & 47.4 & 22.7 & 76.9 & 16.7 & 2.8 & $(b)^{* * *}$ & 98 \\
\hline Functional NL 14 & 6.0 & 26.3 & 68.3 & 39.0 & 1.8 & $(b)^{* * *}$ & 98 \\
\hline Critical NL 16 & 0.6 & 3.21 & 64.0 & 32.6 & 2.9 & $(b)^{* * *}$ & 98 \\
\hline Critical NL 17 & 23.9 & 15.8 & 58.2 & 21.6 & 1.8 & $(c)^{\wedge \wedge \wedge}$ & 98 \\
\hline Graph Interpretation & 9.4 & 14.8 & 63.3 & 26.1 & 2.8 & (b) $* * *$ & 98 \\
\hline
\end{tabular}

(a) $P=0.16$ un-paired t test compared with study group pre-test; (b) $* * * P<0.0001$ Wilcoxon matched pairs signed rank post-test compared with pretest; (c) $M P<0.0001$ paired t test post-test compared with pre-test; $N$, nutrition literacy; $S D$, standard deviation. 


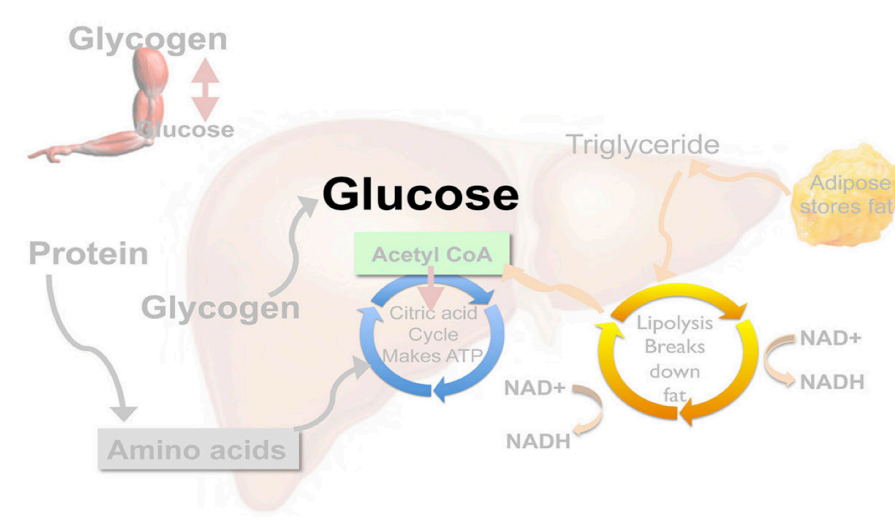

$1 \mathrm{~A}$

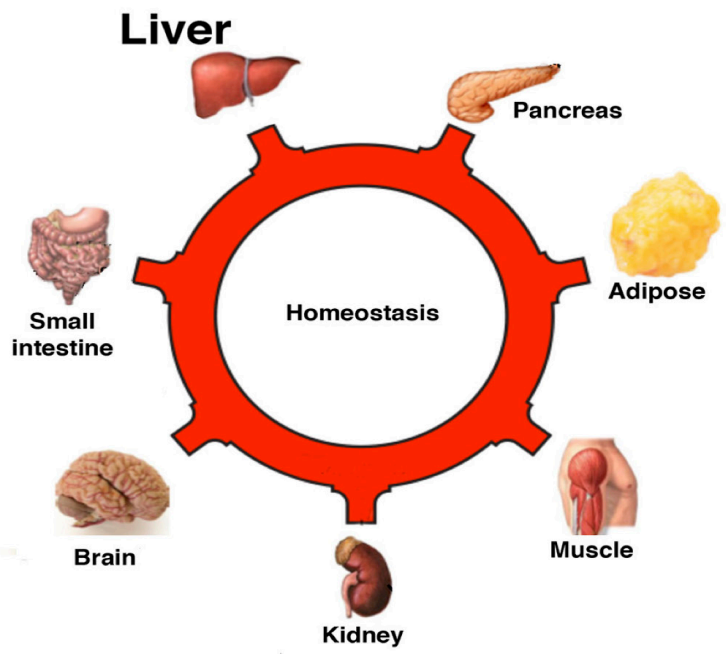

Figure 1: Graphics to illustrate how the curriculum teaches the holistic nature of metabolism and glucose homeostasis. Figure 1A: The liver is illustrated as the master regulator of metabolism responsible for ensuring a sufficient concentration of glucose in the circulation. There is less emphasis on the biochemical details of the citric acid and lipolysis cycles than on their functions to make ATP and break down fat respectively. Figure 1B: The concept of glucose homeostasis is conveyed by illustrating how each organ is connected to the circulation. Whether or not the organs will contribute to or remove glucose from the circulation depends on the physiological status of the body.

Scaffolding CNL onto FNL. A major focus of unit 2 (How does your body use food?) is to explore how the biochemical pathways of carbohydrate, fat, and protein metabolism contribute to the drive to maintain glucose and energy homeostasis under different physiological demands, a key element of FNL. We devised two models to exemplify this concept: (a) the liver is the master regulator that stores, releases or makes glucose as needed; (b) each organ delivers or extracts glucose from the circulation depending on its physiological status e.g. following exercise or during starvation. Students are then asked to predict the behavior of the liver or the organs under different physiological conditions (Figure 1). CNL is scaffolded onto FNL with individual case study scenarios that require students to integrate their FNL knowledge to make health-related decisions (Figure 2). Knowledge and skills assessment probed each domain separately (Table 2). Matched and paired comparison showed that participant significantly increased their pre-post scores in both FNL $(\mathrm{P}<0.0001)$ and $\mathrm{CNL}(\mathrm{P}<0.0001)$ (Table 2$)$.

Integrating CNL with INL. Proficiency in evaluating and interpreting scientific data is a critical element of general scientific literacy, and, with respect to nutrition, the key component of CNL. On the other hand, INL refers to skills in seeking out information. We used two different approaches to probe these concepts: (a) problem-based learning (Strobel and Barneveld, 2009; Krajcik, et al., 2008) and (b) critical evaluation of nutrition claims. In both cases, we employed the Question, Method, Data, Conclusion (QMDC) approach to promote students' evidence-based critical decision making. QMDC is a framework of scientific argumentation that allows scientific studies to be deconstructed (Question: What

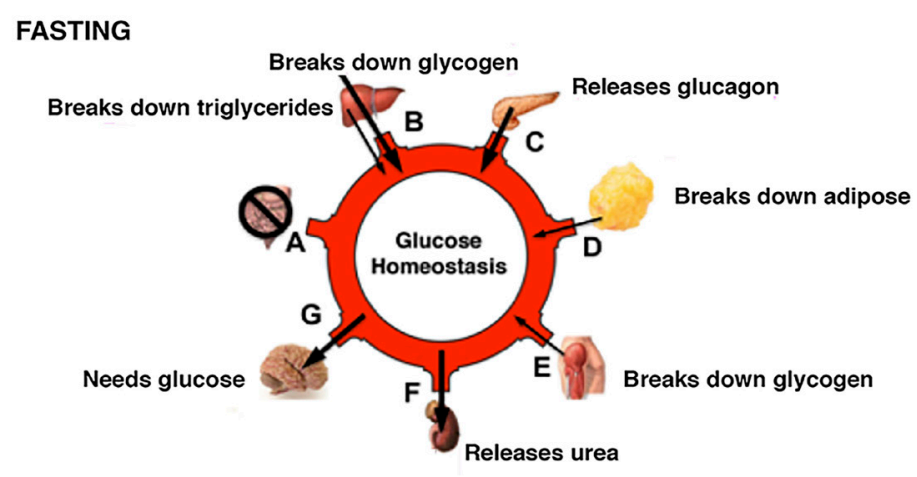

FEASTING

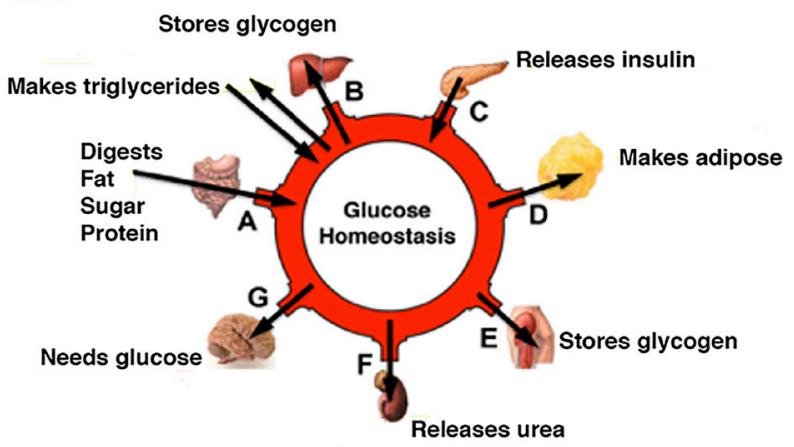

Figure 2: FNL: Understanding the physiological regulation of glucose homeostasis. Students had been given unlabeled glucose homeostasis diagrams with the following instructions: 'In the diagram the circulation is represented by the ring. The upper diagram depicts fasting; the lower diagram depicts feasting. On each diagram 1) Draw arrows that indicate whether each organ pictured is retrieving substances from the circulation or supplying substances to the circulation. 2) Indicate what substance(s) are being retrieved or supplied in each case'. Results are shown in Table 2 (FNL, question 13). 
Table 3: Not all students successfully draw conclusions from data. Students were asked to state the conclusions that could be drawn from a primary scientific paper ${ }^{(26)}$. The range of replies illustrate that not all students have acquired the skill to base conclusions on data.

What conclusions can we draw from this paper? What are the implications for individuals trying to lose weight?

Rubric

As reported by the authors: 'One year after initial weight reduction, levels of the circulating mediators of appetite that encourage weight gain after diet induced weight loss do not revert to the levels recorded before weight loss'. This means that weight regain may relate to the increased drive to eat experienced by individuals that have been dieting. The increase in the drive to eat does not subside within one year after dieting. So long-term strategies may be needed to prevent obesity relapse.

Good

After reading the article we can conclude that although weight loss was achieved immediately through the diet, overweight $\&$ obese people were not able to maintain that weight loss. This is because alterations in hormones involved with body weight persist for 12 months after weight loss which suggests people relapse for physiological reasons. Effects of weight loss include increased levels of grehlin and decreased levels of peptide YY and cholecystokinin. This makes it much harder for obese people to maintain their weight loss because they are hungry frequently.

Acceptable Dieting does not have a sustained weight loss but overall does have loss. After it causes people to want to eat more. This is because people are releasing more grehlin and less 'satiating' hormones. These hormones cause them to regain weight.

Acceptable We can conclude that hormones increase even if a diet is enforced causing weight loss to be difficult for the overweight and obese people to reduce weight. These hormones that are reduced due to weight loss do not continue at the same rate and tend to increase instead. If the hormones increase before a year losing weight will be difficult.

Unacceptable We can draw the conclusion that when dieting the hormone levels in the body do not regulate. This causes less hunger and suppresses the desire to eat. Individuals should change their entire diet for life instead of dieting for a period of time, if they want to lose weight.

is the main purpose of the study? Method: How is the question investigated? Data: What is the evidence for each separate claim? and Conclusion: what conclusions can be made from the evidence? (Wenk and Tronsky, 2011)). The QMDC methodology is helpful because it shows how data is intimately dependent on the methods used, and that any conclusion must arise directly from the data. In the problem-based learning approach students used the QMDC framework to explore a published nutrition study that investigates the response of hunger and satiety hormones to weight loss (Sumithran et al., 2011). In the nutrition claims approach students had to research the evidence for and against a specific nutrition claim, such as a diet (see Supplementary Table 2 for a list of topics) and then critically evaluate the evidence for their classmates who used the QMDC methodology.

The pre-post test showed most students displayed significant improvements in transferring their FNL understanding to interpreting the data: $(\mathrm{P}<0.0001$, Table 2$)$. In addition, they displayed significant improvement in graph interpretation skills, a critical element of NL as well as general scientific literacy $(\mathrm{P}<0.0001$, Table 2$)$. Some students also showed marked improvement in their ability to draw conclusions from the data presented in the individual figures. However, others still struggled with explaining an overall conclusion in the context of the data rather than framed by their own opinions (Table 3). This variation between students suggests that solidly establishing the full range of CNL skills requires a higher dosage of this methodology than the intervention provided.

An important component of INL is the ability to communicate nutrition-related information and ask relevant questions, a skill that must be deployed outside the classroom to promote life-long learning. We assessed behavior change related to INL by comparing the extent to which students were motivated to communicate about NL topics within their social circles (Jacque et al., 2013). As might be expected, most communication about NL occurred among course participants and students also reported a general increase in their communication about the topic with peers $(\mathrm{P}<0.0001$, Table 4). However, communication about NL with family members, other students not in their class and other adults also increased significantly compared with the pre-test $(\mathrm{P}<0.0001$, Table 4).

Establishing life-long learning also depends on an individual's perception of self-efficacy to learn about nutrition. After participating in the curriculum, students' perception of

Table 4: Grouped and Paired Pre-Post changes in communication about NL Topics with Members of Social Network. After the module was over students completed an online retrospective pre-post survey to determine whether participation caused them to share more NL information with members of their social network. Communication increased in every case as measured with the Wilcoxon matched pairs signed rank test. Effect size was determined with Hedge's $g$ (large effect size is $>1$ ).

\begin{tabular}{|c|c|c|c|c|c|c|}
\hline & $\begin{array}{l}\text { Retrospective } \\
\text { Pre-mean }\end{array}$ & (SD) & $\begin{array}{l}\text { Retrospective } \\
\text { Post-mean }\end{array}$ & (SD) & $\begin{array}{l}\text { Effect size } \\
\text { (Hedges' G) }\end{array}$ & $\mathrm{n}$ \\
\hline (a) Aggregate data & 8.3 & 3.5 & $14.2 * * *$ & 5.6 & 1.5 & 77 \\
\hline Family & 1.7 & 1 & $2.6 * * *$ & 1.4 & & \\
\hline Friends & 1.5 & 1 & $2.4 * * *$ & 1.2 & & \\
\hline Students in class & 1.4 & 0.8 & $3.2 * * *$ & 1.6 & & \\
\hline Students in grade & 1.3 & 0.7 & $2.3 * * *$ & 1.1 & & \\
\hline Other adults & 1.3 & 0.7 & $2.0 * * *$ & 1.3 & & \\
\hline Other & 1.3 & 0.7 & $1.8 * * *$ & 1.2 & & \\
\hline $\begin{array}{l}\text { SD, standard de } \\
\text { rank test }\end{array}$ & tion; * & $\overline{0.0}$ & Wilco & tche & pairs sig & \\
\hline
\end{tabular}




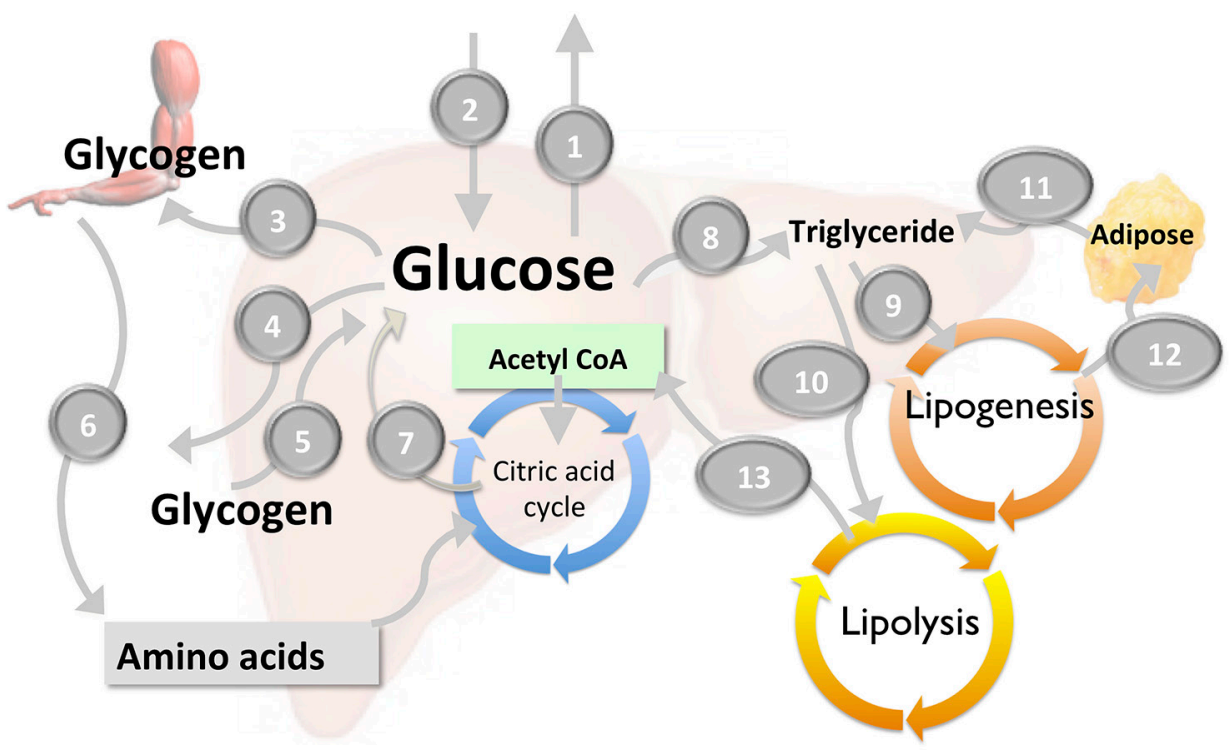

Figure 3: FNL: Understanding glucose homeostasis under physiological conditions. Students had been given this diagram of the liver and then asked the following questions: 'The diagram depicts the pathways involved in metabolizing or synthesizing glucose. Circle the number corresponding to the arrows in pathways that are turned on in each condition indicated'. Answers: Too much blood glucose: 2, 3, 4, 8, 9, 12. Too little blood glucose: 1, 5, 6, 7, 10,11, 13. Results are shown in Table 2 (FNL, question 14).

their capacity to learn about nutrition increased significantly. Comparing the whole cohort, students reported an increase in self-efficacy for finding nutrition information and learning about nutrition topics $(\mathrm{P}<0.0001$, Table 5). These data suggest that the curriculum is effective in improving student attitudes towards their capacity to interpret and evaluate upto-date nutrition claims, critical elements of the independent learning needed to sustain NL in a dynamic health care landscape.

\section{DISCUSSION}

Building NL for the 21 st century requires both understanding current knowledge (FNL) and acquiring the skills to identify and critically evaluate emerging claims (INL and CNL). However, at this time there is a critical disconnect between what is required and what is taught. Nutrition curricula in schools are taught either as part of health education, which commonly focuses on promoting specific behaviors like healthy eating, or in science classes that teach nutrition knowledge, such as the biochemistry of metabolism (FNL). While these same science classes often teach elements of claims evaluation, they rarely target NL specifically. Hence INL and CNL, which focus on the skills to seek out and critically evaluate nutrition information fall through the cracks. Furthermore, it is often assumed that claims evaluation skills will directly transfer from general science classrooms to health-related contexts such as NL, whereas evidence shows such transfer actually requires structured opportunities for targeted practice (Sumithran et al., 2011). Our MD curriculum aimed to remedy these problems: it has a health and disease focus pertinent to nutrition and it was designed to be taught within a science environment that targets general science literacy skills while explicitly integrating all three of the NL subdomains.

This approach successfully impacted skills development in each of the three NL subdomains. Students showed significant improvement in their FNL regarding nutritionally related molecular and cellular biology, biochemistry, anatomy and physiology - concepts that nutrition experts believe pivotal to understanding current issues in nutrition and metabolic diseases. Students also improved their ability to apply this information to real-life scenarios (CNL) as measured by their ability to evaluate health claims in the context of clinical case studies. However, while most participants significantly improved their capabilities to draw conclusions about

Table 5: Grouped and Paired Pre-Post changes in self efficacy related to learning about nutrition and metabolic disease. After the module was over students completed an online retrospective pre-post survey to determine whether participation affected their self-efficacy. Aggregate data indicates a significant increase, as measured with the Wilcoxon matched pairs signed rank test. Effect size was determined with Hedge's g (large effect size is $>1$ ).

\begin{tabular}{lcccccc}
\hline & $\begin{array}{l}\text { Retrospective } \\
\text { Pre-mean }\end{array}$ & (SD) & $\begin{array}{l}\text { Retrospective } \\
\text { Post-mean }\end{array}$ & (SD) & $\begin{array}{l}\text { Effect size } \\
\text { (Hedges' G) }\end{array}$ & $\mathrm{n}$ \\
\hline Aggregate data & 21.9 & 8.35 & $42.3^{* * *}$ & 7.1 & 3.0 & 77 \\
\hline
\end{tabular}

$S D$, standard deviation; $* * * P<0.0001$ Wilcoxon matched pairs signed rank test. 
claims, and especially to interpret graphs, many still struggled to relate overall conclusions to data. This has also been reported as a be a key challenge in general science literacy as "few students systematically demonstrated the difference between evidence and explanations, or could generate explanations from data" (Posner, 2004; Songer, 2003) suggesting that an even higher dose of targeted practice will be required to impact CNL robustly. In response, we have recently designed a QMDC-based curriculum supplement to provide this additional exposure, an approach that has also proved successful in the other Great Diseases modules (Schneider et al., 2018).

The INL skills in communicating and asking questions effectively (Emmons, 2001; Viswanath and Emmons, 2006) are particularly contingent on intrinsic motivation (Martin and Dowson, 2009; Renninger, 1992; Tobias, 1994). However, classroom interventions rely primarily on extrinsic motivators, like grades (Deci et al., 2001) and so are unlikely to be sufficient to promote these skills on their own (Emmons, 2001; Viswanath and Emmons, 2006). Nevertheless, when we measured whether participation in the curriculum increased a behavioral indicator that could be a proxy for intrinsic motivation (students talking more about nutrition topics with members of their social network who were not participants in the curriculum) we found that students did report more communication. However, the conclusions we can draw from these indirect results are limited and the topic deserves further investigation.

Self-efficacy, i.e. the belief in one's capacity to learn about a topic, is considered an important affecter of academic performance, influencing attributes such as effort and persistence when confronting obstacles and failure (Bandura, 1989) as well as fostering the ongoing commitment to independent learning that is required for INL (Berkman et al., 2011; Austin et al., 2012; Basu and Dutta, 2008; Britner and Pajares, 2006; Chen and Zimmerman, 2007). However, the determinants of self-efficacy have still not been clearly identified. Research in other fields has been unable to establish a definitively causal relationship between mastery of knowledge and self-efficacy (Austin et al., 2012; Basu and Dutta, 2008; Britner and Pajares, 2006; Chen and Zimmerman, 2007) and indeed, self-efficacy seems to result more from perception of mastery rather than actual performance (Britner and Pajares, 2006). On the other hand, self-efficacy has been well established to be positively associated with mastery goal orientation (Urdan, 1997) as well as key behavioral constructs such as self-regulation (the ability to set goals for learning and then monitor, regulate, and control cognition and motivation (Chen and Zimmerman, 2007).

Our results clearly showed that students who participate in the curriculum gain significant self-efficacy towards learning about nutrition. While we can't rule out the possibility that factors beyond the curriculum contribute to the in- crease in self-efficacy without a control group, it is unlikely that such factors have a large effect given that related topics are normally absent in high school curricula. Our results also demonstrated that these gains correlate more with behavioral aspects of NL at the intersection between personal and community (Sørensen et al., 2012) than with mastery of NL itself: Thus, self-efficacy correlated more with talking within social networks $(P=0.02$, rho $2=0.26)$ than with the increased mastery of knowledge and skills related to thinking scientifically about nutrition $(\mathrm{P}=0.2$, rho $=0.15)$. Our results confirm the ability of the curriculum to impact both self-efficacy and critical behavioral aspects of INL. Further investigation will be required to establish what parameters of the intervention have been so successful in fostering self-efficacy itself.

Implications for Research and Practice. In the present study, we found that an integrated science-based nutrition curriculum that targets the three distinct subdomains of NL can promote: 1) conceptual knowledge, such as understanding the different components of a healthy diet, how physiological demands dictate how food is used and how the desire to eat intersects with hunger and satiety signals (FNL);2) capabilities to seek out and interpret that knowledge (INL); 3) critical appraisal skills that enable new claims to be evaluated (CNL) (Velardo, 2015). Although we did not address how these NL skills impact behavior, such as dietary and exercise patterns or long-term INL (Laska et al., 2012), our data suggests that science-based nutrition curricula would be a powerful and underexploited addition to 'whole-school model' interventions that incorporate improved food service options with support for family and community to affect nutritional behavior (American Dietetic Association, 2006; Anderson et al., 2005; De Bourdeaudhuij, 2011).

\section{ASSOCIATED CONTENT}

Supplemental material mentioned in this article can be found uploaded to the same webpage as this article.

\section{AUTHOR INFORMATION Corresponding Author}

Berri Jacque. Center for Translational Science Education. Tufts University School of Medicine. 136 Harrison Avenue. Boston, MA 02111.617-636-6913. berri.jacque@tufts.edu.

\section{Author Contributions}

The manuscript was written through contributions of all authors. All authors have given approval to the final version of the manuscript. 


\section{FUNDING SOURCES}

This project was supported by the National Institute of General Medical Sciences through Grant Numbers R25 OD020207 and R25OD010953-04. The funder had no role in the design, analysis or writing of this article.

\section{ACKNOWLEDGMENTS}

The authors would like to thank Dr. Desislava Raytcheva for assistance with grading and Jane Newbold for coordinating curriculum implementation.

\section{ABBREVIATIONS}

CNL: Critical Interpretation and Analysis; CTSE: Center for Translational Science Education at Tufts University School of Medicine; FNL: Functional Use of Factual Knowledge; HL: Health Literacy; INL: Interactive Skills in Seeking Out Information; MD: Metabolic Disease; NL: Nutritional Literacy; QDMC: Question, Method, Data, Conclusion; SD: Standard Deviation

\section{REFERENCES}

Austin, E.W., Pinkleton, B.E., Austin, B.W., and Van de Vord, R. (2012). The relationships of information efficacy and media literacy skills to knowledge and self-efficacy for health-related decision making. Journal of American College Health, 60, 548-554.

Anderson, A.S., Porteus, L.E., Foster, E., Higgins, C., Stead, M., Hetherington, M., Ha, M.A., and Adamson, A.J..(2005). The impact of a school-based nutrition education intervention on dietary intake and cognitive and attitudinal variables relating to fruits and vegetables. Public Health Nutrition, 650-656.

American Dietetic Association. (2006). Position of the American Dietetic Association: individual-, family-, school-, and community-based interventions for pediatric overweight. Journal of the American Dietetic Association, 106, 925.

Bandura, A. (1989). Regulation of cognitive processes through perceived self-efficacy. Developmental Psychology, 25, 729.

Basu, A., and Dutta, M.J. (2008). The relationship between health information seeking and community participation: The roles of health information orientation and efficacy. Health Communication, 23, 70-79.

Berkman, N.D., Sheridan, S.L., Donahue K.E., Halpern, D.J., Viera, A., Crotty, K., Holland, A., Brasure, M., Lohr, K.N., Harden, E., Tant, E., Wallace, I., and Viswanathan, M. (2011). Health literacy interventions and outcomes: an updated systematic review. Evidence Report/Technology Assessment, 199, 1-941.
Berkman, N.D., Sheridan, S.L., Donahue K.E., Halpern, D.J., Viera, A., Crotty, K., Holland, A., Brasure, M., Lohr, K.N., Harden, E., Tant, E., Wallace, I., and Viswanathan, M. (2011). Health literacy interventions and outcomes: an updated systematic review. Evidence Report/Technology Assessment, 199, 1-941.

Britner, S.L., and Pajares, F. (2006). Sources of science self-efficacy beliefs of middle school students. Journal of Research in Science Teaching, 43(5), 485-499.

Centers for Disease Control and Prevention. (2017). National diabetes statistics report. https://www.cdc.gov/diabetes/ data/statistics/statistics-report.html. (accessed December 2018).

Chen, P., and Zimmerman, B. (2007). A Cross-National Comparison Study on the Accuracy of Self-Efficacy Beliefs of Middle-School Mathematics Students. The Journal of Experimental Education, 75, 221-244.

Cohen, A.K., and Syme, S.L. (2013). Education: a missed opportunity for public health intervention. American Journal of Public Health, 103, 997-1001

De Bourdeaudhuij, I., Van Cauwenbergh, E., Spittaels, H., Opert, J.M., Rostami, C., Brug, J., Van Lenthe, F., Lobstein, T., and Maes, L. (2011). School-based interventions promoting both physical activity and healthy eating in Europe: a systematic review within the HOPE project. Obesity Reviews, 12, 205-216.

Deci, E.L., Koestner, R., and Ryan, R.M. (2001). Extrinsic rewards and intrinsic motivation in education: Reconsidered once again. Review of Educational Research, 71, 1-27.

Detterman, D.K., and Sternberg, R.J. (1993). Transfer on trial: Intelligence, cognition, and instruction. Westport, Connecticut: Ablex Publishing.

Emmons, K.M. (2001). Behavioral and social science contributions to the health of adults in the United States, in Promoting Health: Intervention Strategies from Social and Behavioral Research, pp. 254-321. Washington, DC: National Academies Press.

Garet, M.S., Porter, A.C., Desimone, L., Birman, B.F., and Yoon, K.S. (2001). What makes professional development effective? Results from a national sample of teachers. American Educational Research Journal, 38, 915-945.

Haskell, R.E. (2000). Transfer of learning: Cognition and instruction. Elsevier.

Jacque, B., Koch-Weser, S., Faux, R., and Meiri, K.F. (2016). Addressing health literacy challenges with a cutting-edge infectious disease curriculum for the high school biology classroom. Health Education and Behavior, 43, 43-53.

Jacque, B., Malanson, K., Bateman, K., Akeson, B., Cail, A., Doss, C., Dugan, M., Finegold, B., Gauthier, A., Galego, M., Roundtree, E., Spezzano, L., and Meiri, K.F. (2013). The Great Diseases Project: a partnership between Tufts Medical School and the Boston public schools. Academic Medicine, 88, 620 . 
Kindig, D.A., Panzer, A.M., and Nielsen-Bohlman, L. (editors) (2004). Health Literacy: A Prescription to End Confusion. Washington DC: National Academies Press.

Koh, H.K., Berwick, D.M., Clancy, C.M., Baur, C., Brach, C., Harris, L.M., and Zerhusen, E.G. (2012). New federal policy initiatives to boost health literacy can help the nation move beyond the cycle of costly 'crisis care'. Health Affairs (Millwood), 31, 434-443.

Krajcik, J., McNeill, K.L., and Reiser, B.J. (2008). Learninggoals-driven design model: Developing curriculum materials that align with national standards and incorporate project-based pedagogy. Science Education, 92, 1-32.

Laska, M.N., Pelletier, J.E., Larson, N.I., and Story, M. (2012). Interventions for weight gain prevention during the transition to young adulthood: a review of the literature. Journal of Adolescent Health, 50, 324-333.

Malanson, K., Jacque, B., Faux, R., and Meiri, K.F. (2014). Modeling for fidelity: Virtual mentorship by scientists fosters teacher self-efficacy and promotes implementation of novel high school biomedical curricula. PLoS One, 9.

Martin, A.J., and Dowson, M. (2009). Interpersonal relationships, motivation, engagement, and achievement: Yields for theory, current issues, and educational practice. Review of Educational Research, 79, 327-365.

Merriam, S.B., and Leahy, B. (2005). Learning transfer: A review of the research in adult education and training. PAACE Journal of Lifelong Learning, 14, 1-24.

National Research Council. (2012). A Framework for K-12 Science Education: Practices, Crosscutting Concepts, and Core Ideas. Washington, DC: National Academies Press.

Nutbeam, D. (2000). Health literacy as a public health goal: a challenge for contemporary health education and communication strategies into the 21 st century. Health Promotion International, 15, 259-267

Posner, G.J. (2004). Analyzing the curriculum (3rd ed.). New York: McGraw-Hill.

Renninger, K. (1992). The Role of Interest in Learning and Development. Hillsdale, New Jersey: Lawrence Erlbaum Associates, Inc.

Schneider, L., Jacque, B., and Henry, J. (2018). BioSCANN: A collaborative learning platform that scaffolds scientific inquiry in the context of interrupted case studies. International Society of the Learning Sciences, Inc.

Silk, K.J., Sherry, J., Winn, B., Keesecker, N., Horodynski, M.A., and Sayir, A. (2008). Increasing nutrition literacy: testing the effectiveness of print, web site, and game modalities. Journal of Nutrition Education and Behavior, 40, 3-10.

Songer, N.B. (2003). Fostering and measuring the development of complex reasoning in science. In annual meeting of the American Educational Research, Chicago, Illinois.
Sørensen, K., Van den Broucke, S., Fullam, J., Doyle, G., Pelikan, J., Slonska, Z., and Brand, H. (2012). Health literacy and public health: a systematic review and integration of definitions and models. BMC Public Health, 12, 80.

Strobel, J. and van Barneveld, A. (2009). When is PBL more effective? A meta-synthesis of meta-analyses comparing PRL to conventional classrooms. Interdisciplinary Journal of Problem-based Learning, 3, 4 .

Sumithran, P., Prendergast, L.A., Delbridge, E., Purcell, K., Shulkes, A., Kriketos, A., and Proietto, J. (2011). Long-term persistence of hormonal adaptations to weight loss. New England Journal of Medicine, 365, 1597-1604.

Tammen, S., Faux, R., Meiri, K., and Jacque, B. (2018). Collaborative curriculum design as a framework for designing teacher professional development that produces the content knowledge required for teaching the life sciences. Journal of STEM Outreach, 1, 1-7.

Tobias, S. (1994). Interest, prior knowledge, and learning. Review of Educational Research, 64, 37-54.

Urdan, T.C. (1997). Examining the relations among early adolescent students' goals and friends' orientation toward effort and achievement in school. Contemporary Educational Psychology, 22, 165-191.

Velardo, S. (2015). The nuances of health literacy, nutrition literacy, and food literacy. Journal of Nutrition Education and Behavior, 47, 385-389.

Viswanath, K., and Emmons, K.M. (2006). Message Effects and Social Determinants of Health: Its Application to Cancer Disparities. Journal of Communication, 56, S238-S264.

Wenk, L. and Tronsky, K. (2011). First-year students benefit from reading primary research articles. Journal of College Science Teaching, 40, 60 .

Zeldin, A.L., Britner, S.L., and Pajares, F. (2008). A comparative study of the self-efficacy beliefs of successful men and women in mathematics, science, and technology careers. Journal of Research in Science Teaching, 45, 1036-1058. 